\title{
Nanocrystalline Hard Magnetic Materials
}

\author{
M.I. Alymov ${ }^{1}$ I.M. Milyaev², V.S. Yusupov², A.I. Milyaev² \\ ${ }^{1}$ Institute of Structural Macrokinetics and Materials Science of the Russian Academy of Sciences (ISMAN), \\ 8. Chernogolovka, Moscow region, 142432, Russia \\ ${ }^{2}$ Institute of Metallurgy and Materials Science of Russian Academy of Sciences (IMET RAS), \\ 49, Leninsky Prospekt, Moscow, 119991, Russia
}

* Corresponding author: Tel.: + 7 (985) 23835 16; E-mail: milyaev40@mail.ru

\begin{abstract}
The first part of the review covers the results of studies of nanocrystalline single-phase hard magnetic materials, mainly on the basis of compounds of rare earth metals produced by super-fast melt quenching with its subsequent crystallization, mechanical alloying and other rapid solidification techniques such as vapor deposition, etc. Specific features of microstructure, magnetic properties, and mechanisms of magnetic hardening of such alloys are considered. The discussion of magnetic properties of nanocomposite magnets focuses on the exchange interaction of hard magnetic phase with nanoparticles of soft magnetic phase known as the spring interaction effect. The process of magnetic reversal of nanocomposite magnets is discussed.
\end{abstract}

\section{Keywords}

Coercive force; hard magnetite alloy; magnetic anisotropy; maximum energy product; nanocomposite material; rare earth compound; residual induction.

(C) M.I. Alymov, I.M. Milyaev, V.S. Yusupov, A.I. Milyaev, 2017

\section{Introduction}

To date, significant progress has been made in the production of permanent magnets: on sintered anisotropic $\mathrm{Nd}-\mathrm{Fe}-\mathrm{B}$ magnets, a record value of the maximum energy product $(B H)_{\max }=46 \mathrm{~kJ} / \mathrm{m}$ $(57.8 \mu \mathrm{g} \cdot \mathrm{Oe})$ with residual induction $B_{r}=1.533 \mathrm{~T}$ $(15.33 \mathrm{~kg})$ and coercive force $H_{\mathrm{cB}}=776 \mathrm{kA} / \mathrm{m}$ $(9.75 \mathrm{kOe})$ and $H_{\mathrm{cM}}=784 \mathrm{kA} / \mathrm{m}(9.85 \mathrm{kOe})$ has been obtained; industrial production of magnets with $(B H)_{\max } \geq 400 \mathrm{~kJ} / \mathrm{m}(50 \mu \mathrm{g} \cdot \mathrm{Oe})$ has been established [1]. The obtained record value $(\mathrm{BH})_{\max }$ is close to the theoretical limit $(B H)_{\max }^{\text {theor }}=\left(4 \pi M_{S} / 2\right)^{2}=480 \mathrm{~kJ} / \mathrm{m}^{3}$ if $B_{r}=1.55 \mathrm{~T}$ (in the production of anisotropic sintered magnets, it is necessary to introduce a certain amount of a liquid phase additive, which somewhat lowers the residual induction). In the opinion of most researchers and developers of hard magnetic materials, the probability of finding a new intermetallic compound with a higher saturation induction (i.e., more than $1.6 \mathrm{~T}$ ) and with a high uniaxial crystalline magnetic anisotropy in order to obtain more powerful permanent magnets is very low. Considering this point, when developing new hard magnetic materials, more attention has been paid to modern nanotechnologies for the production of various functional materials as nanocrystalline materials possess a number of unusual properties that are of undoubted interest from both a scientific and technological perspectives. At the same time, it is noteworthy that the price-efficiency ratio is another important parameter of hard magnetic materials; various areas of industrial application of permanent magnets include a whole range of different properties of permanent magnets and high values $(B H)_{\max }$ at room temperature are not always dominant.

The properties of materials, in which the size of the crystallites/grains have a nanoscale value, differ from the properties of conventional massive materials because of the increase in the effect of interfaces on the various kinds of interactions in the material. For example, in ferromagnetic 3d-metals, the magnitude of the magnetic moment is determined by the features of the band structure. Near the interface, this value can 
vary sharply due to the compression of the zone caused by a decrease in the coordination environment, and the magnetic moment of the atoms in the nanoparticles becomes larger than in the case of a massive material. In magnetic materials, these unusual properties already find their application in soft and hard magnetic materials, in materials for magnetic recording and they have great prospects in materials for magnetic refrigerators [2].

The theoretical basis of research in the field of nanocrystalline hard magnetic materials remains the dependence of the coercive force on the size of the magnetic particles (Fig. 1), which was found in the 1950s [3]. In accordance with this dependence, the coercive force of the powder permanent magnets increases with decreasing particle size, passing through a maximum when the single-domain state is reached, and then decreases again at an ultra-small size due to the influence of thermal effects and becomes zero at the particle size providing a transition to the superparamagnetic state. For anisotropic materials (either with high crystalline anisotropy or with high form anisotropy) with a sufficiently high saturation magnetization $M_{s}$, the size of the single-domain state is equal to the micron fraction (Table 1) and, therefore, when a microstructure with the size of such particles is realized in the material, we obtain high values of coercive force. It should be noted that such microstructures are obtained both artificially (mainly in REM-based alloys) or naturally by special heat treatment (for example, in alloys of $\mathrm{Fe}-\mathrm{Ni}-\mathrm{A} 1-\mathrm{Co}$, $\mathrm{Fe}-\mathrm{Cr}-\mathrm{Co}$ ).

The first works on production and study of nanocrystalline hard magnetic materials were carried out on amorphous $R-\mathrm{Fe}(R=\mathrm{Tb}, \mathrm{Sm})$ alloys, during the crystallization of which nanosized $\mathrm{RFe}_{2}$ particles with the Laves phase structure and large coercive force at room temperature were obtained [5].

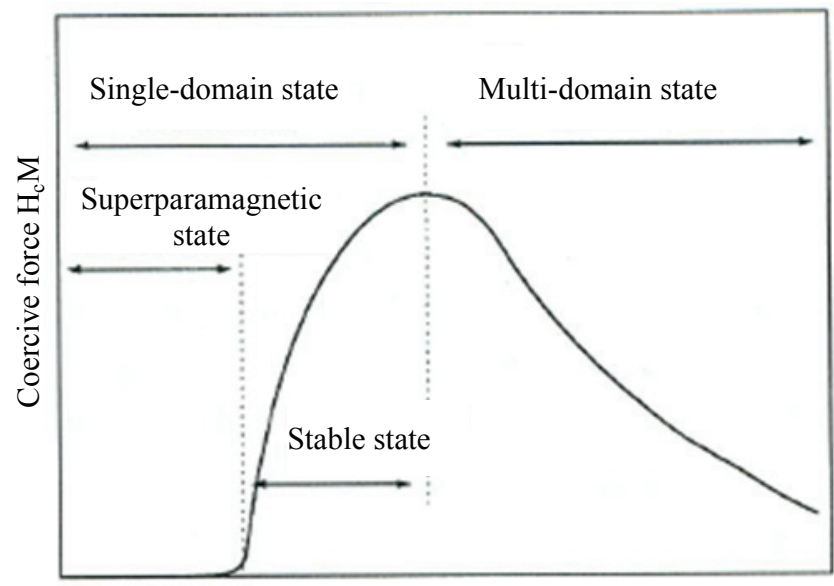

Particle diameter

Fig. 1. Dependence of coercive force $H_{\mathrm{cM}}$ on the particle size (in Hadjipanayis [2])
Table 1

Magnetic properties of some crystalline magnets [4]

\begin{tabular}{lccccc}
\hline \multicolumn{1}{c}{ Magnet } & $M_{s}, \mathrm{~kg}$ & $H_{A}, \mathrm{kOe}$ & $D_{c}, \mu \mathrm{m}$ & $T_{c},{ }^{\circ} \mathrm{C}$ & $H_{c}, \mathrm{kOe}$ \\
\hline $\mathrm{Nd}_{2} \mathrm{Fe}_{14} \mathrm{~B}$ & 16.0 & 67 & 0.25 & 315 & 15 \\
$\mathrm{Pr}_{2} \mathrm{Fe}_{14} \mathrm{~B}$ & 15.6 & 87 & - & 292 & 12 \\
$\mathrm{~Tb}_{2} \mathrm{Fe}_{14} \mathrm{~B}$ & 6.64 & 220 & 1.69 & 356 & 96 \\
$\mathrm{Dy}_{2} \mathrm{Fe}_{14} \mathrm{~B}$ & 7.12 & 150 & - & 320 & 64 \\
$\mathrm{Pr}_{2} \mathrm{Co}_{14} \mathrm{~B}$ & 9.75 & 100 & - & 717 & 25 \\
$\mathrm{Sm}_{1} \mathrm{Fe}_{11} \mathrm{Ti}_{1}$ & 11.7 & 105 & - & 311 & 3.7 \\
$\mathrm{Sm}_{1} \mathrm{Fe}_{10} \mathrm{~V}_{2}$ & 8.0 & 54 & - & 337 & 10 \\
$\mathrm{Sm}_{2} \mathrm{Fe}_{17} \mathrm{~N}_{2,3}$ & 15.4 & 140 & 0.36 & 470 & 30 \\
$\mathrm{Sm}_{2} \mathrm{Fe}_{17} \mathrm{~N}_{2,2}$ & - & $>100$ & - & 400 & 23 \\
$\mathrm{Sm}_{2} \mathrm{Co}_{17}$ & 12.5 & 52 & - & 920 & 9 \\
$\mathrm{SmCo}_{5}$ & 11.4 & $240 \ldots 440$ & $0.71 \ldots 0.96$ & 727 & 50 \\
\hline
\end{tabular}

In the late 1970s, in connection with the general global crisis in the production of cobalt, intensive research was carried out on the study of the REM-based hard magnetic alloys rich in iron, such as $\operatorname{Pr}(\mathrm{Nd})-\mathrm{Fe}$.

The success was achieved in 1983, when G.C. Hadjipanais [6, 7] and J.J. Croat [8], using the melt spinning technology, obtained a large coercive force on the $\mathrm{Pr}-\mathrm{Fe}-\mathrm{B}(\mathrm{Si})$ and $\mathrm{Nd}-\mathrm{Fe}-\mathrm{B}$ alloys, respectively. The large values of the coercive force in both cases were due to the strongly anisotropic tetragonal phase $R_{2} \mathrm{Fe}_{14} \mathrm{~B} \quad\left(K=4.5 \cdot 107 \quad \mathrm{erg} / \mathrm{cm}^{3}\right)$ of the nanoscale value obtained after the crystallization of the spinning flakes [9]. These works have opened new horizons in the field of creation of new hard magnetic materials. Indeed, many other systems based on $11: 12,2: 17,2: 17 \mathrm{~N}(\mathrm{C})_{x}, 3: 29,1: 5$ etc., were then studied with a nanoscale microstructure and with large coercive force values $[10-14]$. In addition to the melt spinning technology, superfast crystallization technologies were studied by casting a melt onto a rapidly rotating copper disk, rapid vapor deposition technology [15 - 17], atomization [18], and mechanical doping [19] to produce nanocrystalline hard magnetic materials. Using the sputtering method, nanomeric $\mathrm{CoPt}$ and $\mathrm{FePt}$ alloys were obtained to produce materials with a high recording density [20,21].

The maximum energy product $(B H)_{\max }$, which characterizes the power of a permanent magnet, depends primarily on the remanent magnetization $M_{r}$ with a theoretical limit $(B H)_{\max }^{\text {theor }}=\left(4 \pi M_{S} / 2\right)^{2}$. Nanocrystalline permanent magnets usually consist of randomly oriented particles and, consequently, their residual induction $M_{r}=M_{S} / 2$ provides low values $(B H)_{\max }$ in comparison with anisotropic permanent magnets. Thus, additional technological operations such as sintering [22] or plastic deformation [23] are 
required to increase $(B H)_{\max }$ of such magnets. It was first discovered that $\mathrm{Nd}-\mathrm{Fe}-\mathrm{B}$ flakes containing a small amount of $\mathrm{Si}$ or $\mathrm{Al}$ have an increased value of the reduced remanent magnetization $m_{r}=M_{r} / M_{S}$ (greater than 0.5) in the isotropic state [24]. Elevated values of $M_{r}$ were associated with a homogeneously fine microstructure with a grain size of 2:14:1 $18 \mathrm{~nm}$ and pure grain boundaries [25]. Later, however, Manaf [26] showed that the presence of Si or Al was not a necessary condition for obtaining increased values of $M_{r}$ in the flakes of the Nd-Fe-B alloy obtained by the melt-spun technology, but it was associated with a controlled process of obtaining a microstructure with a small grain size $(<30 \mathrm{~nm})$. Higher magnetization values are associated with the final texture of magnetized grains due to strong intergranular interaction. Higher values of remanent magnetization were subsequently obtained on composite magnets consisting of a mixture of magnetically hard and soft magnetic phases between which there was an exchange interaction. Coehoorn [27] obtained a reduced remanent magnetization $m_{r}=0.8$ with a coercive force of $H_{\mathrm{cM}}=4 \mathrm{kOe}$ on the melt-spun flakes of the $\mathrm{Nd}_{4} \mathrm{Fe}_{77} \mathrm{~B}_{19}$ alloy consisting of the $\mathrm{Fe}_{3} \mathrm{~B}$ and $\mathrm{Nd}_{2} \mathrm{Fe}_{14} \mathrm{~B}$ phases. It was shown in [28] that flakes consisting of a mixture of $\mathrm{Nd}_{2} \mathrm{Fe}(\mathrm{Co})_{14} \mathrm{~B}+\alpha-\mathrm{Fe}(\mathrm{Co})$ and $\mathrm{Pr}_{2} \mathrm{Fe}(\mathrm{Co})_{14} \mathrm{~B}+\alpha-\mathrm{Fe}(\mathrm{Co})$ phases also had high values of $m_{r}$ and $H_{\mathrm{cM}}$. The same effect was also observed in alloys of other systems, including Sm-Co [29], $\mathrm{Sm}_{2}(\mathrm{Fe}, \mathrm{Co})_{17} \mathrm{~N}_{x}$ [30] and $\mathrm{Sm}_{2}(\mathrm{Fe}, \mathrm{Co})_{17} \mathrm{C}_{x}$ [31]. Acceptable values of $H_{\mathrm{cm}}$ can be obtained in such mixtures, even when the fraction of the hard magnetic phase is only $10 \mathrm{vol} . \%$.

Another class of nanocomposite materials are the precipitation-hardening 2:17 alloys of the composition $\mathrm{Sm}(\mathrm{Co}, \mathrm{Fe}, \mathrm{Cu}, \mathrm{Zr})_{z}$, the $\mathrm{Fe}-\mathrm{Ni}-\mathrm{A} 1-\mathrm{Co}, \mathrm{Fe}-\mathrm{Cr}-\mathrm{Co}$, $\mathrm{Cu}-\mathrm{Ni}-\mathrm{Fe}, \mathrm{Cu}-\mathrm{Ni}-\mathrm{Co}$ alloys. The most impressive results from the point of view of obtaining high values of $(B H)_{\max }$ were obtained on alloys 2:17. The complex microstructure of these massive magnets consists of finely dispersed cells (with cells of phase 2:17, bounded by the walls of phase 1:5) and a system of platelet precipitates (of Z-phase) [32]. The relationship between the size and chemical composition of these phases controls both the magnitude and the temperature dependence $H_{\mathrm{cM}}$.

\section{Nanocrystalline Single-Phase Hard Magnetic Materials}

In the 1980s, nanocrystalline REM intermetallic compounds were used as a tool in the study of new anisotropic phases for permanent magnets by crystallization of an amorphous precursor and determination of the coercive force of crystallization products [33]. In fact, phase 2:14:1 was detected in this way $[6,7]$. Soon it was discovered that such materials have a coercive force significantly greater than the corresponding massive magnets, including sintered magnets. For example, in melt-spun samples of $\mathrm{Nd}_{2} \mathrm{Fe}_{14} \mathrm{~B}$, a coercive force greater than $15 \mathrm{kOe}$ can be easily obtained (see Table 1), while the coercive force of the corresponding sintered magnets is below $10 \mathrm{kOe}$. The higher the anisotropy of the material is, the higher coercive force values are expected. In $\mathrm{Tb}_{2} \mathrm{Fe}_{14} \mathrm{~B}$ and $\mathrm{Dy}_{2} \mathrm{Fe}_{14} \mathrm{~B}$ compounds with an anisotropy field $H_{A} 220$ and $150 \mathrm{kOe}$, respectively, a coercive force of more than $60 \mathrm{kOe}$ was obtained [34].

After the discovery of $R_{2} \mathrm{Fe}_{14} \mathrm{~B}(\mathrm{C})$ compounds with a large coercive force in crystallized melt-spun flakes, a number of other compounds were obtained in the nanocrystalline state and their magnetic properties are shown in Table 1. In the tetragonal $\mathrm{Sm}(\mathrm{Fe}, M)_{12}$ compound, stabilized with small amounts of $M=\mathrm{Mo}, \mathrm{Ti}, \mathrm{V}$, large values of the coercive force were also obtained [35]. Later, strongly anisotropic $\mathrm{Sm}_{2} \mathrm{Fe}_{17} \mathrm{~N}_{x}$ and $\mathrm{Sm}_{2} \mathrm{Fe}_{17} \mathrm{C}_{x}$ compounds were discovered; they were also obtained in the nanocrystalline state [36].

Nanocrystalline single-phase materials have a chemical composition close to the stoichiometric composition of the hard magnetic phase with a minimum number of secondary phases, so the microstructure of such materials is fairly homogeneous, consisting of randomly oriented grains of the hard magnetic phase with clean boundaries, free from the presence of any phases $[9,10]$. Such a microstructure differs drastically from the microstructure of sintered magnets whose composition deviates from stoichiometry towards a larger REM content (firstly, to ensure liquidphase sintering and, secondly, to compensate for REM fumes during sintering) when secondary phases (mainly rich REM) are isolated at grain boundaries. High values of the coercive force are usually easily obtained with a grain size of less than $80 \mathrm{~nm}$. This size is usually smaller than the single-domain size of the particles, which for most highly anisotropic REM magnets is about $\sim 1 \mu \mathrm{m}$ (Table 1 ). The study of the magnetic domain structure of a nanocrystalline $\mathrm{Nd}_{2} \mathrm{Fe}_{14} \mathrm{~B}$ compound [37] showed that, in fact, domain walls cluster around the grain boundaries, again indicating that each grain is one domain. In flakes with a smaller grain size $(<40 \mathrm{~nm})$ in the isotropic state, in addition to large values of $H_{c}$, higher values of the reduced residual magnetization $\left(m_{r}>0.5\right)$ are observed. The presence of large domains [37], the so-called "interaction domains" was revealed; they contain a large number of nanograins and result from the exchange interaction of the spins of neighboring 
grains, aligning the axes of easy magnetization (c-axes) in a certain direction, and creating a network magnetic texture in large areas.

The shape of the hysteresis loop of nanodispersed magnets depends very strongly on their microstructure. When melt-spun flakes are obtained with a cooling rate greater than the critical velocity, $v_{\text {crit, }}$ they are in an amorphous state and have high-permeability. Highcoercivity in such samples is obtained either by annealing or by changing the rotation speed of a watercooled copper disk to reduce the cooling rate and obtain the optimal microstructure. When cooled at a rate less than $v_{\text {crit, }}$ in the samples large grains with low $H_{c}$ are formed. However, surprisingly, as a result of the annealing of such samples, a much finer microstructure is formed and, as a consequence, the highest values of $H_{c}$ are obtained [4].

The initial curve of magnetization of flakes cooled with $v_{\text {crit }}$ indicates that single-domain particles are formed in them. Due to the fact that the grains are randomly oriented (as well as their domains), high values of the magnetic susceptibility are observed in high fields and the saturation magnetization values can be obtained only from the law of approximation to saturation [3]. The resulting remanent magnetization $m_{r}$ of such samples is close to 0.5 , indicating the absence of motion of the domain walls.

The finely dispersed inhomogeneous microstructure of the flakes makes it difficult to discuss the mechanism of reversal magnetization in the framework of either a pure domain wall fixing model or a model for the formation of reverse magnetization nuclei [38]. The first mechanism is supported by the shape of the initial magnetization curve, the field and temperature dependences of the coercive force [38, 39]. Durst and Kronmüller [40], on the other hand, explained the mechanism by the data on the $H_{c}(T)$ dependence. The hysteretic behavior of the flakes is largely characterized by the interaction of single-domain particles, when the interaction of the domains of neighboring grains affects their magnetization reversal. In fact, the initial magnetization curve and the demagnetization curve [41] show that the reversal of the magnetization process at the last stage occurs by simultaneously reversing the magnetic moments of several grains. Magnetization reversal processes in finely dispersed magnets can be better explained within the framework of models of chaotic distribution of anisotropy and micromagnetism fields, which will be discussed somewhat later. Interactions will be much stronger in smaller grains (less than $20 \mathrm{~nm}$ ) and this leads to the appearance of "interaction domains". The coercive force in this case is likely to be controlled by the motion of the domain walls in the "interaction domains".

\section{Nanocomposite Magnets}

Nanocomposite materials with a finely dispersed microstructure, consisting of a mixture of magnetically hard (to obtain high values of $H_{c}$ ) and magnetically soft (for obtaining high magnetization) phases between which there is an exchange interaction attract particular attention as promising materials for obtaining permanent magnets with high values of maximum energy product $(B H)_{\max }$. The exchange interaction leads to the fact that the magnetization vector of the soft magnetic phase coincides with the magnetization vector of the hard magnetic phase, thus leading to an increase in $m_{r}$ greater than 0.5 in the crystallographic isotropic state, while maintaining acceptable values of $H_{c}$. Because of the presence of this interaction higher values of $(B H)_{\max }$ can be expected in comparison with isotropic hard magneticmaterials, in which there is no exchange interaction. Moreover, nanocomposite magnets are of some industrial interest, since they do not need to consume any resources to produce a magnetic texture, and magnets can contain a lesser amount of expensive REMs. To date, a number of nanocomposite magnetic systems, such as $\mathrm{Nd}_{2} \mathrm{Fe}_{14} \mathrm{~B} / \mathrm{Fe}_{3} \mathrm{~B}$ [27], $R_{2} \mathrm{Fe}_{14} \mathrm{~B} / \mathrm{Fe}[28,42-45], R_{2} \mathrm{Fe}_{14} \mathrm{C} / \mathrm{Fe}(R=\mathrm{Nd}, \mathrm{Pr})$, $\mathrm{Sm}_{2} \mathrm{Fe}_{17} \mathrm{~N}_{x R}$ [30], $\mathrm{Sm}_{2} \mathrm{Fe}_{17} \mathrm{C}_{x} / \mathrm{Fe}$ [46], and $\mathrm{Sm}_{2}(\mathrm{Co}$, $\mathrm{Fe})_{17} /(\mathrm{Co}, \mathrm{Fe})[47]$ is in the intensive study. The usual technologies for obtaining massive nanocomposite magnets are melt spinning [28] and mechanical alloying.

The chemical composition of nanocomposite magnets differs from the stoichiometric one because of the presence of soft magnetic phases rich in $\mathrm{Fe}$ and Co, which usually leads to the formation of a finely dispersed two-phase microstructure consisting of $\alpha-\mathrm{Fe}(\mathrm{Co})$ soft magnetic and hard magnetic phases. The greater the amount of the soft magnetic phase is, the higher the residual magnetization is. However, this is due to a significant decrease in the coercive force of $H_{\mathrm{cM}}$. The selection of the composition of such magnets is carried out in such a way as to obtain the optimum value $(B H)_{\max }$. Permanent isotropic magnets with exchange interaction are characterized by a relatively flat demagnetization curve in the second quadrant with a high remanentmagnetization $\left(m_{r}>0.5\right)$ despite the large amount of the soft magnetic phase. The magnetic properties of various nanocomposite systems are given in Table 2.

In most of the systems studied, $m_{r}$ is greater than 0.6. The obtained values of the coercive force strongly depend on the amount of the hard magnetic phase and the features of the microstructure. This is clearly seen 
Table 2 an increase in the average effective

Magnetic properties of nanocomposite magnets [4]

\begin{tabular}{lcccc}
\hline \multicolumn{1}{c}{$\begin{array}{c}\text { Magnetic } \\
\text { composition }\end{array}$} & $\begin{array}{c}\text { Hard } / \\
\text { soft phase }\end{array}$ & $\begin{array}{c}M_{s}, \\
\mathrm{kG}\end{array}$ & $M_{r} / M_{S}$ & $\begin{array}{c}H_{c}, \\
\mathrm{kOe}\end{array}$ \\
\hline $\mathrm{Nd}_{4} \mathrm{Fe}_{78} \mathrm{~B}_{18}$ & $\mathrm{Nd}_{2} \mathrm{Fe}_{14} \mathrm{~B} / \mathrm{Fe}{ }_{3} \mathrm{~B}$ & 12.0 & 0.7 & 3.6 \\
$\mathrm{Nd}_{6} \mathrm{Fe}_{87} \mathrm{Nb}_{1} \mathrm{~B}_{6}$ & $\mathrm{Nd}_{2} \mathrm{Fe}_{14} \mathrm{~B} / \mathrm{Fe}$ & 10.4 & 0.67 & 3.8 \\
$\mathrm{~Tb}_{6} \mathrm{Fe}_{87} \mathrm{Nb}_{1} \mathrm{~B}_{6}$ & $\mathrm{~Tb}_{2} \mathrm{Fe}_{14} \mathrm{~B} / \mathrm{Fe}$ & 4.2 & 0.5 & 1.0 \\
$\mathrm{Dy}_{6} \mathrm{Fe}_{87} \mathrm{Nb}_{1} \mathrm{~B}_{6}$ & $\mathrm{Dy}_{2} \mathrm{Fe}_{14} \mathrm{~B} / \mathrm{Fe}$ & 4.3 & 0.5 & 1.0 \\
$\mathrm{Pr}_{8} \mathrm{Co}_{83} \mathrm{Nb}_{1} \mathrm{~B}_{8}$ & $\mathrm{Pr}_{2} \mathrm{Co}_{14} \mathrm{~B} / \mathrm{Co}$ & 9.0 & 0.6 & 4.3 \\
$\mathrm{Pr}_{8} \mathrm{Fe}_{86} \mathrm{~B}_{6}$ & $\mathrm{Pr}_{2} \mathrm{Fe}_{14} \mathrm{~B} / \mathrm{Fe}$ & 14.2 & 0.68 & 4.9 \\
$\mathrm{Pr}_{8}\left(\mathrm{Fe}_{0.94} \mathrm{Nb}_{0.06}\right)_{86} \mathrm{~B}_{6}$ & $\mathrm{Pr}_{2} \mathrm{Fe}_{14} \mathrm{~B} / \mathrm{Fe}$ & 12.2 & 0.69 & 9.0 \\
$\left.\mathrm{Pr}_{8}\left(\mathrm{Fe}_{0.5} \mathrm{Co}_{0.5}\right)_{0.94} \mathrm{Nb}_{0.06}\right)_{86} \mathrm{~B}_{6}$ & $\mathrm{Pr}_{2}\left(\mathrm{Fe}, \mathrm{Co}_{14} \mathrm{~B} /(\mathrm{Fe}, \mathrm{Co})\right.$ & 13.8 & 0.67 & 2.1 \\
$\left.\mathrm{Pr}_{8}\left(\mathrm{Fe}_{0.5} \mathrm{Co}_{0.5}\right)_{0.94} \mathrm{Nb}_{0.06}\right)_{82} \mathrm{~B}_{10}$ & $\mathrm{Pr}_{2}(\mathrm{Fe}, \mathrm{Co})_{14} \mathrm{~B} /(\mathrm{Fe}, \mathrm{Co})$ & 11.2 & 0.71 & 6.5 \\
$\mathrm{Sm}_{2} \mathrm{Fe}_{15} \mathrm{Cr}_{2} \mathrm{C}_{2}$ & $\mathrm{Sm}_{2} \mathrm{Fe}{ }_{17} \mathrm{C}_{x} / \mathrm{Fe}$ & 8.6 & 0.57 & 12.1 \\
$\mathrm{Sm}_{2} \mathrm{Fe}_{11} \mathrm{Co}_{4} \mathrm{Cr}_{2} \mathrm{C}_{2}$ & $\mathrm{Sm}_{2}(\mathrm{Fe}, \mathrm{Co})_{17} \mathrm{C}_{x} /(\mathrm{Fe}, \mathrm{Co})$ & 8.5 & 0.63 & 9.7 \\
$\mathrm{Sm}_{2} \mathrm{Fe}_{93} \mathrm{~N}_{x}$ & $\mathrm{Sm}_{2} \mathrm{Fe}{ }_{17} \mathrm{~N}_{x} / \mathrm{Fe}$ & 14.0 & 0.79 & 3.9 \\
$\mathrm{Sm}_{10.5} \mathrm{Co}_{49.5} \mathrm{Fe}_{40}$ & $\mathrm{Sm}_{2}(\mathrm{Fe}, \mathrm{Co})_{17} /(\mathrm{Fe}, \mathrm{Co})$ & 15.3 & 0.78 & 3.9 \\
\hline
\end{tabular}

molecular field of the last phase, and as a result, spontaneous magnetization was maintained at temperatures above its usual Curie temperature.

The exchange interaction has a strong temperature dependence and therefore in some nanocomposite systems at low temperatures hard and soft magnetic phases behave individually [28, 54], for example, in the $\operatorname{Pr}_{6} \mathrm{Fe}_{87} \mathrm{Nb}_{1} \mathrm{~B}_{6} / \mathrm{Fe}$ alloy. The loop, measured at $300 \mathrm{~K}$, had a smooth demagnetization curve, whereas the demagnetization curves of loops measured at low temperatures $(10 \ldots 100 \mathrm{~K})$ had a hump, which was more pronounced when the temperature was lower. The coercive force in these systems is composed of the grains of phases 2:14:1 and $\alpha$-Fe grains, which become magnetically hard under the in the examples of the $R_{6} \mathrm{Fe}_{87} \mathrm{Nb}_{1} \mathrm{~B}_{6}$ composition with $R=\mathrm{Tb}$ or $\mathrm{Dy}$, the coercive force in which $(1 \mathrm{kOe})$ is much less than in the melt-spun flakes of $\mathrm{Nd}_{6} \mathrm{Fe}_{87} \mathrm{Nb}_{1} \mathrm{~B}_{6}$, despite the high anisotropy of the phases $R_{2} \mathrm{Fe}_{14} \mathrm{~B}$ ( $R=\mathrm{Tb}$, Dy) [34]. This is due to the formation of larger $\alpha-\mathrm{Fe}$ grains because in these compositions, higher annealing temperatures are required to form the hard magnetic phase.

An interesting property of nanocomposite magnets is their greater degree of reversibility [48] at demagnetization, due to the presence of exchange interaction, allowing these magnets to be called "spring-loaded magnets". For the $\mathrm{Nd}_{6} \mathrm{Fe}_{87} \mathrm{Nb}_{1} \mathrm{~B}_{6} / \alpha-\mathrm{Fe}$ composition, the change in $M_{r}$ is very insignificant in demagnetizing fields up to $2.6 \mathrm{kOe}$, whereas in higher fields irreversible rotation of the magnetization vector occurs, leading to a rapid decrease in $M_{r}$.

Another interesting fact in the behavior of magnets with exchange interaction is an increase in the Curie temperature of the hard magnetic phase, due to the effect of the exchange interaction. Lewis L.H. et.al [49], and also in [50] observed an increase in the Curie temperature of the $R_{2} \mathrm{Fe}_{14} \mathrm{~B}$ phase in $R_{2} \mathrm{Fe}_{14} \mathrm{~B} / \mathrm{Fe}$ nanocomposite magnets. A more significant increase in the Curie temperature of the $2: 17$ phase was obtained in melt-spun nanocomposite magnets with the exchange interaction $\mathrm{Sm}_{2}(\mathrm{Fe}, \mathrm{Co}){ }_{15} \mathrm{Cr}_{2} \mathrm{C}_{2} /(\mathrm{Fe}, \mathrm{Co})$ (by $27^{\circ} \mathrm{C}$ in $\mathrm{Sm}_{2} \mathrm{Fe}_{15} \mathrm{Cr}_{2} \mathrm{C}_{2}$ and by $102{ }^{\circ} \mathrm{C}$ in $\mathrm{Sm}_{2} \mathrm{Fe}_{11} \mathrm{Co}_{4} \mathrm{Cr}_{2} \mathrm{C}_{2}$ ) compared to their cast alloys [51]. An increase in the Curie temperature was due to the penetration of the exchange field of the phase with a higher Curie temperature into the neighboring phase with a lower Curie temperature $[52,53]$. This led to action of the exchange interaction. The coercive force of phase 2:14:1 increases sharply at low temperatures due to a sharp increase in the anisotropy constant $K$, whereas the coercive force of the exchangeinteracting $\alpha-\mathrm{Fe}$ grains increases slightly, leading to the observed demagnetization curve.

On the basis of theoretical analysis [48] and modeling by the methods of micromagnetism [55 - 57] it was shown that the magnetic properties of nanocomposite magnets depend both on the magnetic properties of the constituent phases and on the microstructural features. Kneller E.F. and Hawig R. [48] found that in the microstructure with hard and soft magnetic phases, the exchange interaction was observed if the size of both phases was about double the width of the domain wall of the hard magnetic phase, which was less than $10 \mathrm{~nm}$ for the majority of hard magnetic phases. Fischer R. et al. [57] showed that $M_{r}$ and $H_{\mathrm{cM}}$ decrease with increasing grain size, and magnetic properties deteriorate when an inhomogeneous microstructure is formed. Therefore, microstructure with very small grain sizes of the soft magnetic phase uniformly distributed in the microstructure of the nanocomposite magnets in order to obtain the optimum exchange interaction. Such microstructures can be obtained by optimizing both the composition and the production technology of nanocomposite magnets.

Usually, nanocomposite magnets are obtained from an amorphous state by annealing, during which a microstructure is formed $[19,28]$, which provides the exchange interaction. However, the microstructure it is very important to obtain a homogeneous 
obtained in this way is usually inhomogeneous and the grain size of hard and soft magnetic phases is large enough to provide an optimal exchange interaction. The average grain size for annealed melt-spun flakes of $\mathrm{Pr}_{8} \mathrm{Fe}_{86} \mathrm{~B}_{6}$ alloy, obtained from electron microscopic data, is about $30 \mathrm{~nm}$. The structure is heterogeneous and contains large $\alpha$-Fe grains with sizes up to $50 \ldots 100 \mathrm{~nm}$. To obtain a finer-grained microstructure, alloying elements $M(M=\mathrm{Nb}, \mathrm{Zr}, \mathrm{Cr}$, etc. $)$, which hindered the growth of $\alpha-\mathrm{Fe}$ grains during the crystallization of flakes, were additionally introduced into the alloy $[45,58]$. A much finer-grained and more uniform microstructure with an average grain size of about $15-20 \mathrm{~nm}$ was obtained on the $\mathrm{Pr}_{8}\left(\mathrm{Fe}_{0.94} \mathrm{Nb}_{0.06}\right)_{86} \mathrm{~B}_{6}$ alloy without the presence of large $\alpha-\mathrm{Fe}$ grains $[44,45]$. As a result, the coercive force $H_{c}$ increased from $4.9 \mathrm{kOe}$ in $\mathrm{Pr}_{8} \mathrm{Fe}_{86} \mathrm{~B}_{6}$ to $9.0 \mathrm{kOe}$ in the $\operatorname{Pr}_{8}\left(\mathrm{Fe}_{0.94} \mathrm{Nb}_{0.06}\right)_{86} \mathrm{~B}_{6}$ alloy. A similar effect was obtained when alloying $\operatorname{Pr}_{12} \mathrm{Fe}_{82} \mathrm{~B}_{6}$ with zirconium [55].

The method of cooling melt-spun flakes of nanocomposite alloys with a critical (optimal) cooling rate on a rotating disc allows obtaining a fine-grained microstructure directly from the melt. Nanocomposite magnets from the $R_{2} \mathrm{Fe}_{14} \mathrm{~B} / \mathrm{Fe}$ alloy at the optimum rotational speed of the disk [58] (for the $\mathrm{Pr}_{2} \mathrm{Fe}_{14} \mathrm{~B}$ alloy velocity is about $16.7 \mathrm{~m} / \mathrm{s}$ ) have a homogeneous nanoscale microstructure with fine $\alpha$-Fe grains and, as a result, their magnetic properties $\left(m_{r}, H_{c}\right.$ and $\left.(B H)_{\max }\right)$ are higher in comparison with those of the same nanocomposite alloys obtained from an amorphous state with subsequent annealing. If the cooling rate is less than the optimum, the grain size of the 2:14:1 phases and $\alpha-\mathrm{Fe}$ grains is higher, and if cooling rate is greater than the optimum, partial amorphization of the structure is observed; after crystallization it leads to the formation of large $\alpha$-Fe grains.

A large number of studies have been carried out on the partial replacement of iron by cobalt in nanocomposite magnets in order to improve their thermal stability. It is well known that the Curie temperature of $R_{2} \mathrm{Fe}_{14} \mathrm{~B}$ alloys increases significantly with increasing cobalt content, while the anisotropy field decreases in this case [60]. In addition, the replacement of iron with cobalt leads to an increase in the amount and average size of $\alpha$-Fe grains and to the appearance of small amounts of the $R_{2}(\mathrm{Fe}, \mathrm{Co})_{17}$ phase [45]. Thus, with the introduction of $\mathrm{Co}$, the coercive force decreases from $9.0 \mathrm{kOe}$ in the $\mathrm{Pr}_{8}\left(\mathrm{Fe}_{0.94} \mathrm{Nb}_{0.06}\right)_{86} \mathrm{~B}_{6}$ alloy to $2.1 \mathrm{kOe}$ in the $\operatorname{Pr}_{8}\left(\left(\mathrm{Fe}_{0.5} \mathrm{Co}_{0.5}\right)_{0.94} \mathrm{Nb}_{0.06}\right)_{86} \mathrm{~B}_{6}$ alloy. Later it was found that an increase in boron content in cobalt of substituted magnets promotes the formation of a more uniform and fine-grained microstructure and suppresses the formation of the undesired $R_{2}(\mathrm{Fe}, \mathrm{Co})_{17}$ phase [61], so that the coercive force in such magnets can be partially restored. It is noteworthy that a smooth hysteresis loop with good rectangularity and the magnetic properties $m_{r}=0.7$ and $H_{c}=6.5 \mathrm{kOe}$ were obtained on magnets of the $\operatorname{Pr}_{8}\left(\left(\mathrm{Fe}_{0.5} \mathrm{Co}_{0.5}\right)_{0.94}\right.$ $\left.\mathrm{Nb}_{0.06}\right)_{82} \mathrm{~B}_{10}$ alloy, in which $50 \%$ of $\mathrm{Fe}$ atoms were replaced by Co. On the other hand, in the nanocomposite $\mathrm{Sm}_{2} \mathrm{Fe}_{17} \mathrm{C}_{x} / \mathrm{Fe}$, Co alloy, the substitution of iron with cobalt significantly reduced the size of the $\alpha$-FeCo grains, leading to a greater smoothening of the demagnetization curve and higher values of $m_{r}$ [46]. At elevated temperatures, the coercive force in cobalt replaced alloys was higher, which was associated with an increase in the Curie temperature, although at room temperatures it was somewhat less, which was due to a decrease in the anisotropy field.

The process of crystallization of amorphous alloys plays an important role in the formation of nanocrystalline microstructures. When studying the crystallization of nonstoichiometric alloys on the differential thermal analysis (DTA) and differential scanning calorimetry (DSC) curves, two or three peaks were observed [62], indicating that the transition from an amorphous to an equilibrium crystalline state occurred in stages 2-3. In magnets of $R_{2} \mathrm{Fe}_{14} \mathrm{~B} / \mathrm{Fe}$ alloys, it was found, firstly, that $\alpha$-Fe crystallized first and, secondly, intermediate metastable phases were always formed before the final formation of the $R_{2} \mathrm{Fe}_{14} \mathrm{~B}$ equilibrium phase. The metastable phase in the case of $R=\mathrm{Nd}$ or Pr has a BCC lattice of the $\mathrm{Y}_{3} \mathrm{Fe}_{62} \mathrm{~B}_{14}$ type with a Curie temperature of about $200^{\circ} \mathrm{C}$ [62]. In the $R_{2} \mathrm{Fe}_{14} \mathrm{~B} / \mathrm{Fe}$ alloy, where $R=\mathrm{Tb}$ or Dy, and $\mathrm{Sm}_{2} \mathrm{Fe}_{17} \mathrm{C}_{x} / \mathrm{Fe}$ alloy, the metastable phase with the $\mathrm{TbuC}_{7}$ structure (disordered hexagonal) appears before the formation of the equilibrium phases of $2: 14: 1$ or $2: 17[66,67]$. It follows that the annealing temperature should be high enough to obtain hard magnetic phase and the annealing time must be as small as possible to minimize the growth of $\alpha-\mathrm{Fe}$ grains. It has been found in numerous studies that in most cases the size of the $\alpha$-Fe grains is too large even under optimal annealing conditions and, therefore, additional alloying with elements such as $\mathrm{Nb}, \mathrm{Zr}$ or $\mathrm{Cr}$ should be used to obtain smaller $\alpha-\mathrm{Fe}$ grains, which has been discussed earlier.

The coercive force of hard magnetic materials is usually written in the form $H_{c}=\left(2 K_{1} / \mu_{0} M_{s}\right) \alpha_{k}-N_{\text {eff }} M_{s}$ [64], where $K_{1}$ and $M_{s}$ are the crystalline anisotropy constant and the saturation magnetization of the material, respectively, $\alpha_{k}$ and $N_{\text {eff }}$ are constants that take into account the influence of the microstructure on the crystal field and the local internal field. The first term is a modified magnetic crystalline field in a real 
microstructure caused by various types of inhomogeneities (grain boundaries, secondary phases, impurity atoms, substitutional site, etc.), the second term is a demagnetizing field associated with an irregular shape of the grains.

The process of magnetization reversal of nanocomposite magnets is more complicated in comparison with that of conventional hard magnetic materials, which is connected with the coexistence of hard and soft magnetic phases between which there is an exchange interaction. The general anisotropy constant decreases under the action of the soft magnetic phase, which can be taken into account by replacing $\alpha_{k}$ with $\alpha_{k}^{\prime}=\alpha_{k} \alpha_{\text {ex }}$, where the coefficient $\alpha_{\mathrm{ex}}$ is related to the exchange interaction. It is usually believed that the coercive force is controlled by the mechanism of nucleation of domains of the reverse magnetization in the soft magnetic phase. The nucleation field could be very small if there were no exchange interaction between the magneto-hard and the soft magnetic phases. In the case of the presence of such an exchange interaction, the nucleation field increases significantly and thus provides a high coercive force. This effect is known as "exchange hardening". A theoretical analysis of magnetic hardening in nanocomposite magnets was carried out in a number of works [48, 65], and in [55 - 57] it was studied by the method of micromagnetic modeling. E.F. Kneller and R. Hawig [48], using a onedimensional model, qualitatively explained the large reversibility of induction on the return curves. In accordance with this model, the highest values of the coercive force are obtained when the size of the soft magnetic phase is equal to twice the width of the domain wall of the hard magnetic phase. R. Skomski and J.M.D. Coey [65] theoretically predicted the nucleation field and the energy product of nanocomposite magnets. According to their calculations, the nucleation field reaches a maximum when the diameter of the soft magnetic inclusions in the hard magnetic matrix becomes equal to the width of the Bloch wall of the hard magnetic phase. In [57], it was shown by the method of micromagnetic modeling that the exchange interaction between phases suppresses the nucleation of domains of reverse magnetization and thus provides a high coercive force. It was also shown that $M_{r}$ and $H_{c}$ decreased with increasing grain size and that the magnetic properties deteriorated under the influence of the formation of an inhomogeneous microstructure, which agreed well with the experimental data $[28,45,51]$. All the studies mentioned above show that the coercive force of nanocomposite magnets depends strongly on the anisotropy field of the magnetically solid phase and on the grain size of the soft magnetic phase, which should be of the order of the width of the domain wall of the hard magnetic phase.

\section{Conclusion}

The consideration of the formation of magnetic properties of nanocomposite magnets with finely dispersed microstructure, consisting of a mixture of hard and soft magnetic nanosized phases between which the exchange interaction is realized, shows the possibility of creating constant super magnets with high values of the maximum energy product $(\mathrm{BH})_{\max }$ due to a simultaneous increase in the residual induction $B_{r}$ and the coercive force $H_{c}$.

\section{References}

1. Kaneko Y. "Technological Evolution and Application Trends of NdFeB Sintered Magnets in Japan”. Proceedings of the $18^{\text {th }}$ International Workshop on High Performance Magnets and their Applications, Annecy (France) 29 August - 2 September 2004.

2. Rhull R., Dormann J.L., Fiorani D. (Eds.). "Magnetic Properties of Fine Particles", Amsterdam, North Holland, 1991, p. 161.

3. Morrish A.H. "The Physical Principles of Magnetism”, Wiley, New York, 1965.

4. Hadjipanayis G.C. "Nanophase hard magnets". Journal of Magnetism and Magnetic Materials, 1999, 200, pp. 373-391.

5. Clark A.E. "High-field magnetization and coercivity of amorphous rare - earth - $\mathrm{Fe}_{2}$ alloys". Applied Physics Letters, 1973, v. 23, no. 11, pp. 642-644.

6. Hadjipanayis G.C., Hazelton R.C., Lawless K.R. "New iron - rare - earth based permanent magnet materials". Applied Physics Letters, 1983, vol. 43, no. 8, pp. 797-799.

7. Hadjipanayis G.C., Hazelton R.C., Lawless K.R. "Cobalt-free permanent magnet materials based on ironrare-earth alloys". Journal of Applied Physics, 1984, vol. 55, no. 6, pp. 2073-2077.

8. Croat J.J., Herbst J.F., Lee R.W. and Pinkerton F.E. " $\mathrm{Pr}-\mathrm{Fe}$ and $\mathrm{Nd}-\mathrm{Fe}-$ based materials: A new class of high performance permanent magnets". Journal of Applied Physics, 1984, vol. 55, no. 6, pp. 2078-2082.

9. Herbst J.F., Croat J.J., Pinkerton F.E., Yelon W.B. "Relationships between crystal structure and magnetic properties in $\mathrm{Nd}_{2} \mathrm{Fe}_{14} \mathrm{~B}$ ”. Physical Review B, 1984, vol. 29, no. 7 , pp. $4176-4178$.

10. Pinkerton F.E. and Van Wingerden D.J. "Magnetic hardening of $\mathrm{SmFe}_{10} \mathrm{~V}_{2}$ by melt-spinning". IEEE Transactions on Magnetics, 1989, vol. 25, no. 5, pp. 3306-3308.

11. Ding J., McCormick P.G., Street R. "Structure and magnetic properties of mechanically alloyed $\mathrm{Sm}_{\mathrm{x}} \mathrm{C}_{1-\mathrm{x}}$ ". Journal of Alloys and Compounds, 1993, vol. 191, no. 2, pp. 197-201. 
12. Kuhrt C., Schnitzke K., Schultz I. "Development of coercivity in $\mathrm{Sm}_{2} \mathrm{Fe}_{17}(\mathrm{~N}, \mathrm{C})_{\mathrm{x}}$ magnets by mechanical alloying, solid -gas reaction and pressure - assisted zinc bounding". Journal of Applied Physics, 1993, vol. 73, no. 10 , pp. $6026-6028$.

13. Shen B.G., Kong L.S., Wang F.W. and Cao L. "Structure and magnetic properties of $\mathrm{Sm}_{2} \mathrm{Fe}_{14} \mathrm{Ga}_{3} \mathrm{C}_{\mathrm{x}}$ ( $\mathrm{x}=0-2,5)$ compounds prepared by arc malting". Applied Physics Letters, 1993, vol. 63, no. 16, pp. 2288-2290.

14. Nasunjilegal B., Yang F.M., Tang N., Qin W.D., Wang J.L., Zhu J.J., Guo H.Q., Hu B.P., Wang Y.Z., Li H.S. "Novel permanent magnetic material: $\mathrm{Sm}_{3}(\mathrm{Fe}, \mathrm{Ti})_{29} \mathrm{~N}_{\mathrm{y}}$ ". Journal of Alloys and Compounds, 1995, vol. 222, pp. 57-61.

15. Yang C.J., Kim S.W., Kang J.S. "Magnetic properties of $\mathrm{NdFeB}$ thin films grown by a pulsed laser deposition". Journal of Magnetism and Magnetic Materials, 1988, vol. 188, pp. 100-108.

16. Sellmyer D.J. "Magnetism of nanostructured rare earth multilayers and films". Journal of Alloys and Compounds, 1992, vol. 181, no. 1-2, pp. 397-408.

17. Fullerton E.E., Jang J.S., Grimsditch M., Sowers C.H., Bader S.D. "Exchange - spring behavior in epitaxial hard/soft bilayers". Physical Review B, 1998, vol. 58, no. 18, pp. 12193-12200.

18. Narasimhan K., Willman C., Dulis E.J. US. Patent No 4,588,439, 1986.

19. McCormick P.G., Miao W.F., Smith P.A.I., Ding J., Street R. "Mechanically alloyed nanocomposite magnets". Journal of Applied Physics, 1998, vol. 83, no. 11, pp. 6256-6261.

20. Liu J.P., Liu Y., Luo C.P., Shan Z.S., Sellmyer D.J. "High energy products in rapidly annealed nanoscale $\mathrm{Fe} / \mathrm{Pt}$ multilayers". Applied Physics Letters, 1998, vol. 72, no. 4, pp. 483-485.

21. Starroyiannis S., Panagiotopoulos I. N., Niarchos D., Christodoulides J., Zhang Y., Hadjipanayis G.C. "CoPt/Ag nanocomposites for high density recording media". Applied Physics Letters, 1998, vol. 73, no. 23, pp. 3453-3455.

22. Sagawa M., Fujimura S., Togawa N., Yamamoto H., Matsuura Y. "New material for permanent magnets on a base of $\mathrm{Nd}$ and Fe". Journal of Applied Physics, 1984, vol. 55, no. 6, pp. 2083-2087.

23. Lee R.W., Brewer E.G., Schaffel N.A. "Processing of neodymium - iron - boron melt-spun ribbons to fully dense magnets". IEEE Transactions on Magnetics, 1985, vol. MAG-21, no. 5, pp. 1958-1963.

24. McCallum R.W., Kadim A.M., Clemente G.B., Keem J.E. "High performance isotropic permanent magnet based on $\mathrm{Nd}$ - Fe - B". Journal of Applied Physics, 1987, vol. 61 , no. 8 , pp. 3577-3579.

25. Hadjipanayis G.C., Gang W. "Magnetic hysteresis in melt-spun $\mathrm{Nd}-\mathrm{Fe}-\mathrm{Al}-\mathrm{B}-\mathrm{Si}$ alloys with high remanence". Journal of Applied Physics, 1988, vol. 64, no. 10 , pp. 5559-5561.

26. Manaf A., Zhang P.Z., Ahamad I., Davies H.A., Buckely R.A. "Magnetic properties and microstructural characterization of isotropic nanocrystalline $\mathrm{Fe}-\mathrm{Nd}-\mathrm{B}$ based alloys". IEEE Transaction on Magnetics, 1993, vol. 29 , no. 6 , pp. $2866-2868$.
27. Coehoorn R., Mooji D.B., de Waard C. "Meltspun permanent magnet materials containing $\mathrm{Fe}_{3} \mathrm{~B}$ as the main phase", Journal of Magnetism and Magnetic Materials, 1989, vol. 80, no. 1, pp. 101-104.

28. Hadjipanayis G.C., Withanawasam L., Krause R.F. Nanocomposite $\mathrm{R}_{2} \mathrm{Fe}_{14} \mathrm{~B} / \alpha-\mathrm{Fe}$ permanent magnets". IEEE Transaction on Magnetics, 1995, vol. 31, no. 6, pp. 3596-3601.

29. Grabbe M.W., Davies H.A., Buckley R.A. "Remanence enhancement in nanostructured melt-spun $\mathrm{Sm}\left(\mathrm{Fe}_{0.209} \mathrm{Cu}_{0.061} \mathrm{Zr}_{0.025} \mathrm{Co}_{0.704}\right)_{7.61}$ ”. IEEE Transaction on Magnetics”, 1994, vol. 30, no. 2, pp. 696-698.

30. Ding P.G., McCormick P.G., Street R. "Remanence enhancement in mechanically alloyed isotropic $\mathrm{Sm}_{7} \mathrm{Fe}_{93}-$ nitride". Journal of Magnetism and Magnetic Materials, 1993, vol. 124, no. 1-2, pp. 1-4.

31. Ding J., McCormick P.G., Street R. "A study of $\mathrm{Sm}_{13}\left(\mathrm{Co}_{1-\mathrm{x}} \mathrm{Fe}_{\mathrm{x}}\right)_{87}$ prepared by mechanical alloying". Journal of Magnetism and Magnetic Materials, 1994, vol. 135, no. 2, pp. 200-204.

32. Hadjipanayis G.C. Proceedings of the Third International Symposium on Magnetic Anisotropy and Coercivity in Rare Earth TM Alloys, Austria, Baden, 1982, p. 609.

33. Hadjipanayis G.C. "The use of rapid solidification processes in search of new hard magnetic materials". Canadian Journal of Physics, 1987, vol. 65, no. 10, pp. 1200-1209.

34. Pinkerton F.E. "High coercivity in melt-spun Dy $\mathrm{Fe}-\mathrm{B}$ and $\mathrm{Tb}-\mathrm{Fe}-\mathrm{B}$ alloys". Journal of Magnetism and Magnetic Materials, 1986, v. 54-57, part 1, pp. $579-582$.

35. Coehoorn R., Duchateau J.P.W.B. and Denissen C.J.M. "Permanent magnetic materials based on $\mathrm{Nd}_{2} \mathrm{Fe}_{14} \mathrm{C}$ prepared by melt spinning". Journal of Applied Physics, 1989, vol. 65, no. 2, pp. 704-709.

36. Handstain A., Kubis M., Cao L., Gebel B., Müller K-H. "Termostability and magnetic properties of $\mathrm{Sm}_{2}(\mathrm{Fe}, \mathrm{M})_{17}(\mathrm{C}, \mathrm{N})_{\mathrm{y}}(\mathrm{M}=\mathrm{Ga}, \mathrm{Al}$ and $\mathrm{Si})$ ". Journal of Magnetism and Magnetic Materials, 1999, vol. 192, pp. 281-287.

37. Hadjipanayis G.C., Gong W.J. Magn. Magn. Mater., 1997, vol. 66, p. 390.

38. Herbst J.F., Croat J.J. "Neodymium - iron - boron permanent magnets". Journal of Magnetism and Magnetic Materials, 1991, vol. 100, no.1-3, pp. 57-58.

39. Hadjipanayis G.C., Dickerson B.C., Lawless K.R. "The microstructure and magnetic properties of melt-spun $\mathrm{Fe}_{76} \mathrm{Nd}_{16} \mathrm{~B}_{8}$ magnetic materials". Journal of Magnetism and Magnetic Materials, 1986, vol. 54-57, part 1, pp. 557-558.

40. Durst K.D., Kronmüller H. "The coercive field of sintered and melt-spun NdFeB magnets". Journal of Magnetism and Magnetic Materials, 1987, vol.68, no. 1, pp. 63-75.

41. Zhao S., Jin H., Wang X, Yan Y. "Magnetization reversal process for $\mathrm{Nd}_{2} \mathrm{Fe}_{14} \mathrm{~B}$ crystal covered by an $\alpha$-Fe surface layer". Journal of Magnetism and Magnetic Materials, 2002, vol. 239, pp. 25-37.

42. Manaf A., Buckley R.A., Davis H.A. "New nanocrystalline high-remanence $\mathrm{Nd}-\mathrm{Fe}-\mathrm{B}$ alloys by rapid 
solidification". Journal of Magnetism and Magnetic Materials, 1993, vol. 128, no. 3, pp. 302-306.

43. Withanawasam L., Hadjipanayis G.C., Krause R.F. "Enhanced remanence in isotropic $\mathrm{Fe}$ - rich melt-spun $\mathrm{Nd}-$ Fe - B ribbons". Journal of Applied Physics, 1994, vol. 75, no. 10 , pp. 6646-6648.

44. Chen Z.M., Zhang Y., Ding Y.Q., Hadjipanayis G.C., Chen Q., Ma B.M. "Magnetic properties and microstructure of nanocomposite $R_{2}(\mathrm{Fe}, \mathrm{Co}, \mathrm{Nb}){ }_{14} \mathrm{~B} /(\mathrm{Fe}, \mathrm{Co})(R=\mathrm{Nd}, \mathrm{Pr})$ magnets". Journal of Applied Physics, 1999, vol. 85, no. 8, pp. 5908-5910.

45. Chen Z.M., Zhang Y., Ding Y.Q., Hadjipanayis G.C., Chen Q. and Ma B.M. "Studies on magnetic properties and microstructure of melt-spun nanocomposite $R_{8}(\mathrm{Fe}, \mathrm{Co}, \mathrm{Nb})_{86} \mathrm{~B}_{6} \quad(R=\mathrm{Nd}, \quad \mathrm{Pr})$ magnets". Journal of Magnetism and Magnetic Materials, 1999, vol. 195, no. 2, pp. 420-427.

46. Chen Z.M., $\quad$ Ni C.Y., $\quad$ Hadjipanayis G.C. "Microstructure and magnetic properties of melt-spun $\mathrm{Sm}_{2} \mathrm{Fe}_{15-\mathrm{x}} \mathrm{Co}_{\mathrm{x}} \mathrm{Cr}_{2} \mathrm{C}_{2}(x=0-4)$ nanocomposite magnets". Journal of Magnetism and Magnetic Materials, 1998, vol. 186, pp. 41-48.

47. Smith P.A.I., Ding J., Street R., McCormick P.G. "Mechanically alloyed Sm - (Co-Fe) permanent magnets". Scripta Materialia, 1996, vol. 34, no. 1, pp. 61-66.

48. Kneller E.F., Hawig R. "The exchange-spring magnet: a new material principle for permanent magnets". IEEE Transaction on Magnetics, 1991, vol. 27, no. 4, pp. 3588-3600.

49. Lewis L.H., Welch D.O., Panchanathan V. "Curie temperature enhancement of $\mathrm{Nd}_{2} \mathrm{Fe}_{14} \mathrm{~B}$ in nanocomposite exchange-spring alloys". Journal of Magnetism and Magnetic Materials, 1997, vol. 175, no. 3, pp. 275-278.

50. Ddahlgren M., Grossinger R., de Morais E., Gama S., Mendoza G., Liu J.F., Davis H.A. IEEE Trans. Magn., 1997, vol. 33, 3895 p.

51. Chen Z.M., $\quad$ Daniil M., Hadjipanayis G.C., Moukarika A., Papaefthymiou V. "Enhancement of Curie temperature of the 2:17 phase in nanocomposite $\mathrm{Sm}_{2}(\mathrm{Fe}, \mathrm{Co}){ }_{15} \mathrm{Cr}_{2} \mathrm{C}_{2} /(\mathrm{Fe}, \mathrm{CO})$ magnets". Journal of Appluyв Physics, 1999, vol. 86, no. 7, pp. 3857-3862.

52. Hernando A., Navarro I., Gorria P. "Iron exchangefield penetration into the amorphous interphase of nanocrystalline materials". Physical Review B, 1995, vol. 51, no. 5, pp. 3281-3284.

53. Hernando A., Navarro I., Prados C., Garcia D., Lesmes F., Freijo J.J., Saledo A. Nanostructured Materials, 1997, vol. 9, 459 p.
54. Goll D., Seeger M., Kronmüller H. "Magnetic and microstructural properties of nanocrystalline exchange coupled PrFeB permanent magnetic". Journal of Magnetism and Magnetic Materials, 1998, vol. 185, no. 1, pp. 49-60.

55. Schrefl T., Fischer R., Fidler J., Kronmüller H.J. "Two and three-dimensional calculation of remanence enhancement of rare-earth based composite magnets". Journal of Applied Physics, 1994, vol. 76, no. 10, pp. 7053-7058.

56. Fischer R., Schrefl T., Kronmüller H. J., Fidler J. "Phase distribution and computed magnetic properties of high-remanent composite magnets". Journal of Magnetism and Magnetic Materials, 1995, vol. 150, no. 3, pp. 329-344.

57. Kronmüller H.J., Fischer R., Schrefl T., Fidler J. "Grain-size dependence of remanence and coercive field of isotropic nanocrystalline composite permanent magnets". Journal of Magnetism and Magnetic Materials, 1996, vol. 153, no. 1-2, pp. 35-49.

58. Chen Z., Zhang Y., Hadjipanayis G.C., Chen Q., Ma B.M. "Effect of wheel speed and subsequent annealing on the microstructure and magnetic properties of nanocomposite $\mathrm{Pr}_{2} \mathrm{Fe}_{14} \mathrm{~B} / \alpha$-Fe magnets". Journal of Magnetism and Magnetic Materials, 1999, vol. 206, pp. 8-16.

59. Goll D., Kronmüller H. Proceedings of the $15^{\text {th }}$ Workshop on REPM and their Applications, Dresden, Germany, September 1998, p. 189.

60. Buschow K.H.J., Handbook of Magnetic Materials, vol. 10, Elsevier, Amsterdam, 1997, p. 463.

61. Fuerst C.D., Herbst J.F. "Hard magnetic properties of melt-spun $\mathrm{Nd}$ - $\mathrm{Co}-\mathrm{Fe}$ - B materials". Journal of Applied Physics, 1988, vol. 63, no. 8, pp. 3324-3326.

62. Withanawasam L., Murphy A.S., Hadjipanayis G.C., Krause R.F. "Nanocomposite $\mathrm{R}_{2} \mathrm{Fe}_{14} \mathrm{~B} / \mathrm{Fe}$ exchange coupled magnets". Journal of Applied Physics, 1994, vol. 76, no. 10, pp. 7065-7067.

63. Tang W., Jing Z.Q., Zhang J.R., Zhang S.Y., Du Y.W. "Structural and magnetic evolution of rapidly quenched $\mathrm{Sm}-\mathrm{Fe}-\mathrm{Si}-\mathrm{C}$ alloys". Journal of Applied Physics, 1997, vol. 82, no. 10 , pp. 5054-5056.

64. Vonsovsky S.V. Magnetism: the magnetic properties of diam-, para-, ferro-, antiferro- and ferrimagnetics. M. : Nauka, 1971. 1032 p. (Rus)

65. Skomski R., Coey J.M.D. "Giant energy product in nanostructured two-phase magnets". Physical Review B, 1993, vol. 48, no. 21, pp. 15812-15816. 